\title{
The Role of Lev Shubnikov in the Development of Low-Temperature Physics and Technology in Ukraine
}

This article explores the scientific research carried out and organised by Lev Vasilevich Shubnikov in the field of low-temperature physics in Ukraine in the 1930s. The article discusses the founding of the scientific school of cryogenics under his lead and the repressions of the Soviet government against the scientific elite of Ukraine.

Shubnikov was a distinguished experimental physicist, Doctor of Physics and Mathematics. In 1926, he graduated from the Leningrad Polytechnic Institute. In 1926-1930, he worked at the Leiden Low Temperature Laboratory in Netherlands. In 1931-1937, Shubnikov was the director of the Cryogenic Laboratory at the Ukrainian Physical-Technical Institute in Kharkov, and in 1934-1937 he was professor at the Kharkov University and head of the Department of Solid State Physics, part of the Faculty of Physics and Mathematics. In 1937, Shubnikov was arrested and sentenced to death by firing squad.

The year 2018 marked the passing of 105 years since the Nobel Prize in Physics was awarded to Kamerlingh Onnes for the study of the properties of matter at low temperatures, which led to the production of liquid helium. In 1908, at the Leiden laboratory, the Dutch scientist Kamerlingh Onnes managed, for the first time in history, to obtain liquid helium, which is the most difficult substance to liquify. In 1911, he started to study the physical properties of superpurity metals at low temperatures (Dahl, 1984).

Development in the field of low-temperature physics was relatively slow until the beginning of the 1940s. Researchers distinguish between two phases: the first period lasted until the 1930s, when the field of low-temperature physic was poorly studied and there was only one laboratory of low temperatures-the Leiden laboratory. While possessing unique technical capabilities to conduct research close to absolute zero, scientists tried to determine the possible area of practical use of their experiments.

At the beginning of the 1930s, a new phase started in the development of lowtemperature physics, lasting until the early 1940s. During this period, more than ten new laboratories were established worldwide, including the Ukrainian 
laboratory, which was opened at the Kharkov Physical Technical Institute under the supervision of Lev Shubnikov, and others in the US, England, Germany, Canada, Switzerland, etc. (Karelin, 2009)

The development of low-temperature physics in Ukraine is related to the founding of the Ukrainian Physical-Technical Institute (UPTI) in Kharkov in 1928 and its subsequent activities. The institute was organised on the initiative of Academician Abram Ioffe. The staff of the Leningrad Physical-Technical Institute (now the Ioffe Institute) were involved in the start of the future UPTI. Ivan Obreimov was appointed as the institute's first director (KIPT, n.d.).

Research in the field of low-temperature spectroscopy of molecular crystals, which was started in the late 1920s by Academician Ivan Obreimov, showed the need to create a special cryogenic laboratory at the institute. At the beginning, the laboratory was used to carry out research only in crystal spectroscopy. However, the range of researches expanded rapidly (Lazarev, 2010). In 1930, after his internship in Leiden, Lev Shubnikov, a physicist with a wide range of interests, came to Kharkov.

Lev Shubnikov was born on 29 September 1901. In 1926, he graduated from the Leningrad Polytechnic Institute and became an engineer-physicist. After graduation from the institute, Shubnikov was sent to do internship in Netherlands and this became a very important period in Shubnikov's scientific work (1926-1930) (Balabekian, 1966).

At the Leiden Cryogenic Laboratory named after Kamerlingh Onnes, Shubnikov was entrusted by Professor de Haas with the task to obtain perfect bismuth monocrystals to undertake exact research in electric conductivity at low temperatures and in external magnetic field. Until that time, research in this field had been attempted only with crystalline samples of bismuth from industrially manufactured large crystals. All these experiments yielded different results simply because the samples were damaged during the manufacturing process. Using artificial crystals as samples was expected to give good and precise results.

Cooperating with de Haas, Shubnikov was able to obtain crystals of bismuth, rare for their perfection and purity, by using a slightly changed and improved Kapitsa's method of growing monocrystals of bismuth from the melt.

Their method allowed to grow crystals based on previously set geometry and with a set position of crystallographic axes (Shubnikov \& de Haas, 1930). Having obtained perfect bismuth monocrystals by using their original method, 
Shubnikov and de Haas started to study its electric properties in a magnetic field at low temperatures. This research led to the discovery of a new, previously unknown phenomenon of periodic changes in resistance of bismuth regarding a magnetic field, which came to be called the Shubnikov-de Haas effect (Brandt \& Chudinov, 1982).

The significance of each research is measured by its influence on the development of various fields of physics. From this perspective some could say that the scientific works of Shubnikov and de Haas in 1930, in the course of which the oscillating reliance of the resistance of bismuth based on a magnetic field and also the first quantum effect in solid state (the Shubnikov-de Haas effect) were discovered, could be fully appreciated only now.

After becoming the scientific adviser of the Cryogenic Laboratory of UPTI in 1931, Shubnikov started research in the field of low temperatures. Under his supervision, the instruction in the new cryogenic equipment was carried out, hydrogen and helium machines were installed, and the apparatus for liquefying helium with the Kapitsa method was built. He was also responsible for the formation and training of the new technical and cryogenic staff, which was the first professional personnel in the institute and the USSR.

Alongside fundamental research, applied researches related to the use of deep cooling in industry for the separation of air and coke oven gas, for the production of liquid methane, etc. were also held at the laboratory. In 1933, Shubnikov came up with an initiative to create a specialized technical laboratory, which was supposed to be a link between science and industry. In 1935, a structure called the Experimental Deep-Cooling Station (EDCS) was founded. The EDCS, along with the UPTI, made a great contribution to the development of engineering cryogenics.

In Kharkov, research of superconductivity has been extremely prolific for a long time. Outstanding successes in this field were associated with the works of L. Shubnikov, B. Lazarev, N. Alekseevsky, V. Khotkevich, Y. Shepelev, Y. Ryabinin and other physicists (Slezov, Papirov \& Shepelev, 2009).

Successes in the development of low-temperature physics and technology had proved its significance by 1937, so that in January that year, a field session of the USSR Academy of Sciences was held in Kharkov. The event went down in history as the First All-Union Conference on Cryogenics, and emphasized the authority of Lev Shubnikov, his students and staff in these areas. 
The results of their research on superconductivity were presented in a scientific article. In June 1936, an article by the staff of the Ukrainian Physical-Technical Institute, 'Magnetic properties of superconducting metals and alloys' by Shubnikov, Khotkevich, Shepelev, and Ryabinin was published in a special issue of the journal Physikalische Zeitschrift der Sowjetunion (Schubnikow et al., 1936). The article was received by the editors on 11 April 1936. Publication of this issue was timed to coincide with the VI International Congress on Cold (held in the Hague in 1936).

The congress was organized by the International Institute of Refrigeration (IIR). IIR was created in 1908 during the First International Congress of Refrigeration, held in Paris, at the same time when the intergovernmental organisation called the International Association for Refrigeration was established (in 1920 it was renamed to IIR). The announced main goal of the new association was to be wide exchange of experience, scientific and technical achievements and other information in all fields of application of artificial cooling (Timofeev, 2011). However, for the students of Ukraine, participation in the activities of this organization was difficult due to the policy of the country's leaders to limit communication between Ukrainian students and their colleagues abroad.

In that situation, international scientific and cultural ties played a positive role, the conditions for which, as the researchers note, were created by the Treaty of Rapallo, signed on 16 April 1922. The third article of this treaty stated a renewal of diplomatic relations between the RSFSR and Germany.

The provisions of the Treaty of Rapallo were extended to Ukraine on November 5, 1922. The traditional scholarly ties of Ukrainian scientists that had existed until 1917, received a new impetus with the introduction of the norms of the Treaty of Rapallo (Ukrainian SSR.., 1966). This contributed to the fact that two foreigners-Martin and Barbara Ruhemann-were employed at the Shubnikov cryogenic laboratory. The Ruhemanns had British citizenship and were originally from Germany. Martin Ruhemann headed (since 1934) an experimental station for deep cooling. His wife-Barbara Ruhemann-worked as a physicist in the low-temperature laboratory. The curious fact is, that, according to the results of the work carried out at the UPTI in 1935, Martin Ruehmann was awarded as one of the best workers of socialist labor (Savchuk, 2007).

As a foreign citizen, Martin Ruhemann had the opportunity to take part in the Hague Congress and, since Shubnikov was not allowed to travel abroad, 
Ruhemann distributed Shubnikov's publication among the participants of the Congress of Refrigeration and gave a report on this work. Shubnikov greatly appreciated this work. The paper was sent to the press in 1936, not only to be published in the issue of Physikalische Zeitschrift der Sowjetunion (Schubnikow et al., 1936), but also in Zhurnal Eksperimentalnoi i Teoreticheskoi Fiziki (Journal of Experimental and Theoretical Physics, JETP) (Shubnikov et al., 1937). In the special edition of the Ukrainian Journal of Physics (2008, vol. 53), dedicated to the 90th anniversary of the NAS of Ukraine and to the contribution of Ukrainian scientists to the Golden Fund of the World Science, this article was reprinted in English (Shubnikov et al., 2008).

In 1935, the arrest of the theoretical physicist Moissey Koretz, who worked for Lev Landau, brought about the so-called Koretz case, in which Martin Ruhemann and Barbara Ruhemann were involved in the investigation process as foreign experts because, like Koretz, they were against the development of defence subjects at the UPTI. The case was closed, but the atmosphere of suspicion towards the scientists remained.

The Koretz case was one of the first in a series of repressions by the authorities against the UPTI officers. The UPTI case is a general term for repressions directed against the physicists of the Ukrainian Physical-Technical Institute (Kharkov) in 1935-1937. A total of 11 members of the UPTI suffered from reprisals, five of them were shot: L. Shubnikov, L. Rozenkevich, V. Gorsky, V. Fomin and $\mathrm{K}$. Weisselberg, two foreigners (members of the Communist Party of Germany) were issued by the Gestapo: F. Houtermans and A. Weissberg. As a result of the activities of the NKVD, the Nobel-level experimental physicist Shubnikov was destroyed, the UPTI ceased to exist as a center of theoretical and experimental physics on the European level, and Friedrich Houtermans was sent to Nazi Germany and was involved in the development of nuclear weapons. Alexander Weissberg, who was sent to Gestapo, was in German concentration camps and prisons in 1940-1945, but survived (Pavlenko, Ranyuk \& Khramov, 1998). In April 1957, Lev Shubnikov was posthumously rehabilitated by the Military Collegium of the Supreme Court.

After the death of Shubnikov in 1937, the traditions of his low-temperature school were continued in the activities of the laboratory, which since 1938 was headed by Boris Lazarev. Stalin's repressions destroyed a number of the best representatives of Ukrainian science, culture, and social thought. One of the worst things to think about in this regard is the tragedy of the untapped potential - the discoveries that were never made, the books that were never written. We can 
only speculate what could have been the contribution of one of the most gifted Ukrainian physicists, Lev Shubnikov, to the development of physics and all of humanity. After all, he was shot at the age of 36 .

The scientific research of Lev Shubnikov was devoted to solid state physics and low-temperature physics. He developed a method for growing single crystals from the melt (the Obreimov-Shubnikov method). Together with de Haas, he discovered (in 1930) oscillations of the electrical resistance of bismuth in a magnetic field at the temperature of liquid helium (the Shubnikov-de Haas effect).

Lev Shubnikov was a pioneer of Ukrainian low-temperature physics. In Kharkov, he successfully mastered the cryogenic technique, installed helium and hydrogen liquefiers, and laid the foundation for extensive research in the field of superconductivity, low-temperature magnetism, and the physics of cryogenic liquids. In 1931, he obtained liquid hydrogen, in 1932-liquid helium; he also carried out the first researches in the country to study the physical properties of liquefied gases, in particular, he measured the viscosity of liquid nitrogen, oxygen, carbon monoxide, argon, methane, ethylene (in 1934). In 1934, together with Y. Ryabinin (almost simultaneously with V. Meissner and R. Ochsenfeld) he directly showed that in the superconducting state the magnetic induction of metal is zero. He established (in 1934-1937) the main features of the behavior of homogeneous superconducting alloys in a magnetic field, discovered the existence of two critical magnetic fields and the so-called Shubnikov phase (in fact, experimentally discovered superconductors of type II) (Slezov, Papirov \& Shepelev, 2008). In 1936, he received the first proof of Silsbee's conjecture on the nature of the destruction of superconductivity by electric current. He was the first to observe antiferromagnetism (in 1935). In 1936, in cooperation with Lazarev, he measured the nuclear magnetic moment of solid hydrogen.

He was the founder of the Ukrainian scientific school of cryogenics. A huge number of Ukrainian scientists, known for outstanding world-class results, came out of this school: B. Lazarev, N. Alekseevsky, L. Vereshchagin, B. Verkin, A. Galkin, B. Eselson, S. Zlunitsyn, A. Kikoin, N. Nakhimovich, N. Rudenko, A. Sudovtsov, O. Trapeznikova, M. Fyodorova, V. Hotkevich, and G. Shepelev.

The Shubnikov program of research in the field of low-temperature physics covered a wide range of problems, anticipating the development of this field of science for many years. It is enough to note three outstanding scientific results of Lev Shubnikov which are rated worthy of the Nobel Prize: 
- Discovery of the first quantum oscillation effect in metals, called the Shubnikov-de Haas effect;

- Discovery of second-type superconductors and Shubnikov phases;

- Detection of a mixed and intermediate state of type I superconductors.

Taking into account the significance of the works of Lev Shubnikov, in 2001, the Presidium of the National Academy of Sciences of Ukraine adopted the Decree on the Establishment of the Lev Shubnikov Prize for outstanding work in the field of experimental physics (NAS Ukraine, 2001). The world's scientific community highly recognised Shubnikov's contribution to the development of low-temperature physics. According to a report by Ted G. Berlincourt at the Symposium dedicated to the 75 th anniversary of the discovery of superconductivity (held in USA in 1986): "Shubnikov and his co-authors made a decisive experiment and correctly interpreted it" (Berlincourt, 1987). In the US, the title "Shubnikovskiy Professor" was established and this title was given to the Director of the Center for Applied Superconductivity, Professor David Larbalestier from the University of Wisconsin, Madison.

\section{Liubov Sukhoterina}

Odessa National Polytechnic University

\section{References}

Balabekian, O. (1966), 'Lev Vasilievich Shubnikov', Uspekhi Fizicheskikh Nauk, vol. 89, no. 2, pp. 321-325. https://doi.org/10.3367/UFNr.0089.196606i.0321

Berlincourt, T. G. (1987), 'Type II superconductivity: quest for understanding,' IEEE Trans. Magnetics, V.MAG-26, no. 2, pp. 403-412. https://doi.org/10.1109/TMAG.1987.1065156

Brandt, N. \& Chudinov, S. (1982), 'The Shubnikov-de Haas effect and its application to the energy spectrum of metals, semimetals and semiconductors,' Uspekhi Fizicheskikh Nauk, vol. 137, no. 7, pp. 479-499. Retrieved from https://ufn.ru/ ufn82/ufn82_7/Russian/r827f.pdf [accessed 20 Feb 2019] https://doi.org/10.3367/UFNr.0137.198207f.0479

Dahl, P. F. (1984), 'Kamerlingh Onnes and the discovery of superconductivity: The Leiden years 1911-1914,' Historical Studies in the Physical Sciences, vol. 15, pp. 1-38. https://doi.org/10.2307/27757541

Karelin, P. K. (2009), 'Fizika nizkikh temperatur (Kratkii istoricheskii ocherk)' [Physics of low-temperature (a short history overview)], in P. K. Karelin (ed.) Sobytiia, liudi, dela, zhizn'.., Omsk: NTK “Kriogennaia Teknika,” pp. 10-21. Retrieved from 
http://www.cryontk.ru/media/files/3_fizika_niz_temp.pdf [accessed 20 Feb 2019]

KIPT (n.d.), 'History,' National Scientific Center Kharkov Physical-Technical Institute. Retrieved from https://www.kipt.kharkov.ua/bhr.html [accessed 20 Feb 2019]

Lazarev, B. G. (2010), $K$ istorii kriogennoi laboratorii UFTI [History of cryogenic laboratory UPTI]. Retrieved from http://ftint50.ilt.kharkov.ua/pdf/ch1_3.pdf [accessed 20 Feb 2019]

NAS Ukraine (2001), Shubnikov Prize. Retrieved from http://www.nas.gov.ua/UA/ Competition/Pages/Default.aspx?CompetitionID=072 [accessed 20 Feb 2019]

Pavlenko, Y; Ranyuk, Y. \& Khramov, Y. (1998), “Delo” UFTI, 1935-1938 [The UPTI Case, 1935-1938], Kyiv: "Phoenix" of the UANNP.

Savchuk, V. (2007), 'Cooperation of physicists of Soviet Ukraine, Germany and Austria: 1920-30s (on the example of Kharkov and Dnepropetrovsk),' in V. Savchuk (ed.) Questions of German History, vol. 33, pp. 346-355.

Schubnikow, L. W.; Chotkewitsch, W. I.; Schepelew, J. D. \& Rjabinin, J. N. (1936), 'Magnetische Eigenschaften supraleitender Metalle und Legierungen,' Phys. Z. Sowjet., vol. 10, no. 2, pp. 165-192.

Shubnikov, L. \& de Haas, W. J. (1930), 'Neue Erscheinungen bei der Widerstandsänderung von Wismuthkristallen im Magnetfeld bei der Temperatur von flüssigem Wasserstoff,' Leiden Comm. Kamerlingh Onnes Lab, nos. 207, 207a, 210a, 210b; Proc. Amst. Acad. Sci., vol. 33, no. 5, pp. 418-438.

Shubnikov, L.; Khotkevich, V.; Shepelev, Y. \& Ryabinin, Y. (1937), 'Magnitnye svoistva sverkhprovodiashchikh metallov i splavo' [Magnetic properties of superconducting metals and alloys], Zhurnal Eksperimentalnoi i Teoreticheskoi Fiziki ZhETF, vol. 7, no. 2, pp. 221-237.

Shubnikov, L. V.; Khotkevich, V. I.; Shepelev, Yu. D. \& Ryabinin, Yu. N. (2008), 'Magnetic properties of superconducting metal and alloys,' (transl. and reprinted from $Z h E T F)$, Special Issue of Ukr. J. Phys, vol. 53, pp. 42-52.

Slezov, V.; Papirov, I. \& Shepelev, A. (2008), 'Otkrytie sverkhprovodnikov II roda (faza Shubnikova)' [The discovery of the Shubnikov phase (type II superconductors)], Bulletin of Kharkiv University, no. 823, Physics Series "Kernels, particles, fields", vol. 3, no. 39, pp. 120-129.

Slezov, V.; Papirov, I. \& Shepelev, A. (2009), 'Kratkaia istoriia otkrytiia sverkhprovodnikov II roda (fazy Shubnikova)' [A short history of discovering of superconductors of the second kind (Shubnikov phase)], Voprosy Atomnoi Nauki i Tekniki, no. 6, Series: Vakuum, chistye materialy sverkhprovodniki, pp. 86-92.

Timofeev, V. (2011), 23rd International Congress of Refrigeration 'Refrigeration business,' no. 9, pp. 20-28. Retrieved from http://holod-delo.ru/icr2011.pdf [accessed 20 Feb 2019]

Ukrainian SSR... (1966), Ukrayins'ka RSR na mizhnarodnij areni: Zb. dokumentiv (1917-1923 pp.) [Ukrainian SSR on the international Українська scene: collection of documents (1917-1923)], Kyiv: Nauk. dumka. 